\title{
APPLICATION OF MIND MAP IN TEACHING GEOMETRY IN GRADE 4
}

\author{
Lu Kim Ngan", \\ Duong Huu Tong', \\ Bui Phuong Uyen', \\ Nguyen Duc Minh ${ }^{4}$ \\ ${ }^{1}$ Master Student, \\ Can Tho University, \\ Can Tho City, \\ Vietnam \\ ${ }^{2,3}$ Can Tho University, \\ Can Tho City, \\ Vietnam \\ ${ }^{4}$ Pre-service teacher, \\ Can Tho University, \\ Can Tho City, \\ Vietnam
}

\begin{abstract}
:
When it comes to mathematics education and learning, mind maps are a graphical representation of ideas and concepts widely used. A mind map can significantly improve student learning and teacher teaching activities by its unique structure and characteristics. This study demonstrates the feasibility and effectiveness of incorporating a mind map into the geometry curriculum for fourth-grade students. The findings of an experiment conducted on 44 primary students demonstrate that, with the teacher's guidance, most students can create an appropriate mind map to review a lesson and that the mind map contributes to increasing students' learning motivation and subject interests. Several students responded positively to a survey about their attitudes toward using mind maps in mathematics learning, which revealed that they have favorable attitudes toward using mind maps.
\end{abstract}

Keywords: mind map, learning motivation, students' attitudes, primary students

\section{Introduction}

Mind maps, which a psychologist developed, mathematician and brain researcher Tony Buzan in the late 1960s (D'Antoni et al., 2010; Erdem, 2017; Mamontova et al., 2016; Wang

i Correspondence: email dhtong@ctu.edu.vn 
et al., 2014), are multi-sensory tools that utilize visuospatial orientation to integrate information, and consequently, assist students to organize and retain information (D'Antoni et al., 2010; Mamontova et al., 2016).

In a mind map, text content is represented visually, and the connections between different levels of hierarchy and stages of development are shown (Anas et al., 2018; Katagall et al., 2015; Pribadi \& Susilana, 2021; Santiago, 2011; Serrat, 2017). In line with this, Buzan and Buzan (2006) defined a mind map as a radial branch-like visual organizer in which concepts are structured hierarchically or associatively (as cited in Stokhof, 2019; Merchie et al., 2021). According to Liu et al. (2015), a mind map consists of words or concepts (with verbal and symbolic elements (Dhindsa, 2011), colors and pictures (D'Antoni, 2010; Merchie et al., 2021)) connected by lines with associated prepositional phrase where a line indicates the relationship between the words (Liu et al., 2015). A mind map, in particular, is a network or nonlinear diagram that begins with a key or main idea in the center and expands outward from there to include subtopics radially around the main idea. The subtopics group and similar cluster ideas branch out to lower-level topics (Arthur, 2012; D'Antoni et al., 2010; Dhindsa et al., 2011; Serrat, 2017).

According to Buzan (2005), there are four important features of a mind map, including: (1) attention to the subject is provided by a picture at the center of the diagram; (2) main topics of the subject are formed thanks to the branches regarding the picture at the center; (3) branches state a key picture or keyword on the connected lines; and (4) branches have a structure related to each other (as cited in Erdem, 2017). In addition, lines closer to the center should be thicker than those far from the center; the employment of images tagged to the branches is encouraged; and the use of color, especially for grouping and encoding, is also recommended (Santiago, 2011). These characteristics align with the points of view in the research of Bhattacharya and Mohalik (2020).

Figure 1 illustrates a mind map.

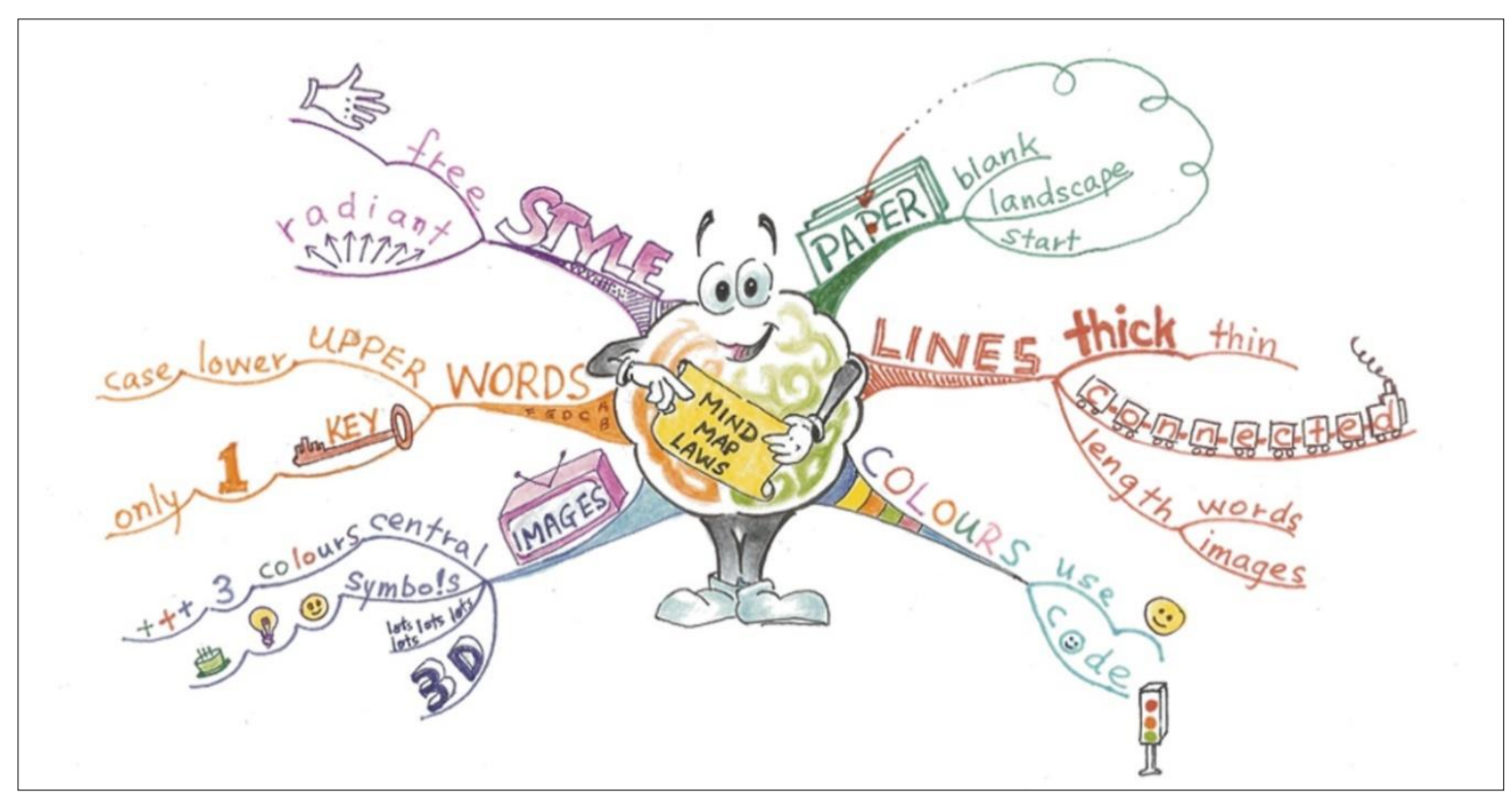

Figure 1: An example of a mind map (derived from Tony Buzan Learning Centre) 
According to Norman (2012), a mind map can serve various functions. They can be used to depict the information presented in an informational text (representation), provide a classifying framework for text information (organization), explain abstract ideas by depicting them more concretely (interpretation), or provide mnemonics to help readers remember the text by making it more concrete and meaningful (transformation) (Norman, 2012). Many researchers concluded that the structure of the mind map aligns with the brain's neural network (Merchie et al., 2021), and the mind map itself taps into the natural nonlinear thinking process of the brain and potentiate learning by using both left-right brain capacities (Erdem, 2017; Santiago, 2011).

Research by Stokhof et al. (2019) and Stokhof et al. (2020) has shown that mind maps, especially digital mind maps, are suitable for primary education. Five specific characteristics shown in Stokhof et al. (2019) include: (1) mind maps support recording, exchanging and comparing information (Näykki \& Järvelä, 2008); (2) mind maps have a flexible structure in which relations between concepts are easily visualized (Eppler, 2006); (3) fast elaboration and continuous alterations in the conceptual structure are made possible by digital mind maps in particular (Eppler, 2006); (4) Digital mind maps can serve as data repositories for storing and exchanging new information (Tergan, 2005); and (5) Building a mind map necessitates adherence to a few simple rules: To create branches, start with a single word, then split them at the end and add text on top. Color should be used consistently throughout (Buzan \& Buzan, 2006), and according to Merchie and Van Keer (2012), even elementary school students should have no problem learning and applying these guidelines (as cited in Stokhof et al., 2019).

A few advantages of using mind maps have been outlined by Serrat (2017), including (1) the process of creating a mind map is more interesting and entertaining than writing a report or drawing up a standard chart or table, and (2) mind maps can be used to visualize information; (2) Because of mind maps' visual quality, users can more easily identify, clarify, classify, summarize, consolidate, highlight, and present a subject's structural elements than with a standard set of notes; (3) While linearly taking notes, keywords and images are more easily forgotten when using mind maps to organize your thoughts. The advantages of mind maps include their compactness, lack of extraneous words, ease of drawing, flexibility, and ability to condense pages of information into a single visual representation; and (5) In order to fill in information gaps and make complex issues more understandable, using mind maps can be beneficial (Serrat, 2017).

Previous studies have proved many benefits when applying mind maps in the teaching and learning process. Due to the mind map's characteristics, it contributes to more intensive collective knowledge construction as well as more effective information organization (Cendros Araujo \& Gadanidis, 2020; D'Antoni et al., 2010; Dhindsa et al., 2011; Erdem, 2017; Mamontova et al., 2016; Pribadi \& Susilana, 2021; Stokhof et al., 2019; Stokhof et al., 2020). Thus, according to Dhindsa et al. (2011); Santiago (2011); Liu et al. (2015); D'Onofrio et al. (2017); Erdem (2017); Anas et al. (2018); Merchie et al. (2021); Pribadi and Susilana (2021), mind maps help students to promote the occurrence of longterm memory. For the brain, a mind map, which is multi-colored, multi-dimensional and provides visually stimulating stimulation, is more attractive than one colored traditional 
note and more effective in remembrance (Erdem, 2017). Furthermore, Santiago (2011) and Brandner (2020, as cited in Pribadi \& Susilana, 2021) showed that mind maps can facilitate students in structuring information, helping to analyze, comprehend, synthesize, recall and generate new ideas better. Therefore, mind maps can positively affect students' conceptual understanding (Anas et al., 2018; Dhindsa et al., 2011), critical thinking (Anas et al., 2018; D'Antoni et al., 2010; Dhindsa et al., 2011; Pribadi \& Susilana, 2021; Santiago, 2011) and creativity thinking (D'Onofrio et al., 2017; Erdem, 2017). On the other hand, using mind maps in the classroom also improves students' interaction (Cendros Araujo \& Gadanidis, 2020; Dhindsa et al., 2011; Liu et al., 2015) and motivation (Anas et al., 2018; Erdem, 2017; Stokhof et al., 2019). In a study on pre-service mathematics teachers, Cendros Araujo and Gadanidis (2020) described their interaction while engaging in collaborative mind mapping. Firstly, participants develop discourse by adding comments, asking questions, sharing life experiences, and referring to class activities and resources. Moreover, secondly, they also develop leadership by engaging in behaviors such as building a base, making aesthetic decisions, resolving technical issues, giving directions, grouping topics, highlighting, filling or leaving blanks, and overcoming leadership obstacles (Cendros Araujo \& Gadanidis, 2020).

Because of its benefits, mind maps are widely applied in teaching and learning in our day. It enables students to develop problem-solving capabilities, highlighting opinions, note-taking, recalling information, and tasks preparation and organization (Buran \& Filyukov, 2015). Mind maps can be utilized as note-taking in learning-teaching, and they are an effective technique. -taking that differs significantly from the traditional note-taking method taking shape, aiding in remembrance with its colorful structure and links based on the active use of both lobes of the brain, making it convenient for constructivist learning (Erdem, 2017). Mind mapping is commonly used for the following purposes: (1) taking notes during meetings, whether individual or group; (2) summarizing the discussion: (3) to generate new ideas and viewpoints that lead to better solutions; (4) to simplify complex concepts; (5) to provide an overview of the gathered data; (6) to provide simple and creative information by the provided format (Elmansy, 2020; as cited in Pribadi \& Susilana, 2021).

Along with conventional mind maps, an interactive mind map is an effective tool for new teaching and learning application of modern technology (Anas et al., 2018; Cendros Araujo \& Gadanidis, 2020; Liu et al., 2015; Maksimenkova et al., 2018; Mamontova et al., 2016). There are lots of available software that allow the creation of mind maps, such as Blummind, FreeMind, XMind, GoConqr, MindMup2, WiseMappinf, MindMeister, MINDMAP 9, Mindjet MindManager, Coggle (Cendros Araujo \& Gadanidis, 2020; Liu et al., 2015, Maksimenkova et al., 2018; Mamontova et al., 2016; Santiago, 2011). In addition, researchers have studied the method of presenting a mind map online. Accordingly, Liu et al. (2015) developed a web application that provides an interface allowing users to create a knowledge mind map. With the online mind map tool, the electronic learning resource will be discovered and shared in the form of a subjectoriented package (Liu et al., 2015). 
Nevertheless, using a mind map for teaching and learning creates some challenges for mind map adaptation (Maksimenkova et al., 2018). In general, grading students' mind maps is one of the challenges teachers have to overcome. Assuredly, teaching with a mind map requires the teacher to gather students' mind maps and evaluate them. Evaluation, in this case, is the process with rising laboriousness. The great difficulty of evaluation makes educational mind mapping a poor scalable technique. With a digital mind map, the first challenge is a selection of software suitable to educational needs. However, the automatization of this process can increase scalability. So, the questions of automatic mind maps evaluation are on the front of the burner (Maksimenkova et al., 2018).

The question of educational mind map evaluation is quite complicated and requires exact and consistent grading rules (Maksimenkova et al., 2018). According to Stokhof et al. (2020), to determine if students attained curricular objectives, three quality indicators in the student mind maps were operationalized: similarity to the core curriculum, elaboration of the core curriculum, and structure quality (Stokhof et al., 2020). D'Antoni et al. (2010) developed the mind map assessment rubric (MMAR) using weighted scores including concept links, cross-links, hierarchies, examples, invalid components, pictures and colors (D'Antoni et al., 2010; Santiago, 2011). Besides, Maksimenkova et al. (2018) introduced the automatic grader for educational mind maps (AGEMM) which acts like a teacher's assistant and calculates several quantitative metrics. Results demonstrate that the AGEMM may be transformed to scales or criteria levels used to evaluate (Maksimenkova et al., 2018).

\section{Research Objectives}

Geometry is an important branch in the mathematics curriculum of primary education, which provides students with practical knowledge associated with real life. Due to the intellectual characteristics of primary students, the teaching of geometric elements cannot yet be based on deduction but mainly on visualization to help them approach basic geometric features and properties of some geometric figures. Due to the need to innovate methods of teaching mathematics and other subjects in primary school, as well as the benefits of using mind mapping in teaching, the study aims to:

1) Analyze primary students' ability to use mind maps to support learning geometry.

2) Analyze students' attitudes towards using mind maps in learning geometry.

\section{Research Methodology}

\subsection{Participants}

The experiment was conducted with 44 students in grade 4 of Mac Dinh Chi Primary School in Can Tho City, Vietnam.

\subsection{Procedure and Instrument}

\subsubsection{Procedure}

The experiment was divided into two phases. 
Phase 1: Letting students get acquainted with mind map by introducing about mind map, instructing how to draw a mind map and color the designed mind map of "Parallelogram".

- Teacher gives a brief introduction about the mind map so that students can understand: What is a mind map? What are the usages of the mind map? What are the advantages of a mind map over conventional memorization and note-taking? How to draw a mind map?

- Instructing students to color in the designed mind map of the lesson "Parallelogram" (Figure 2).

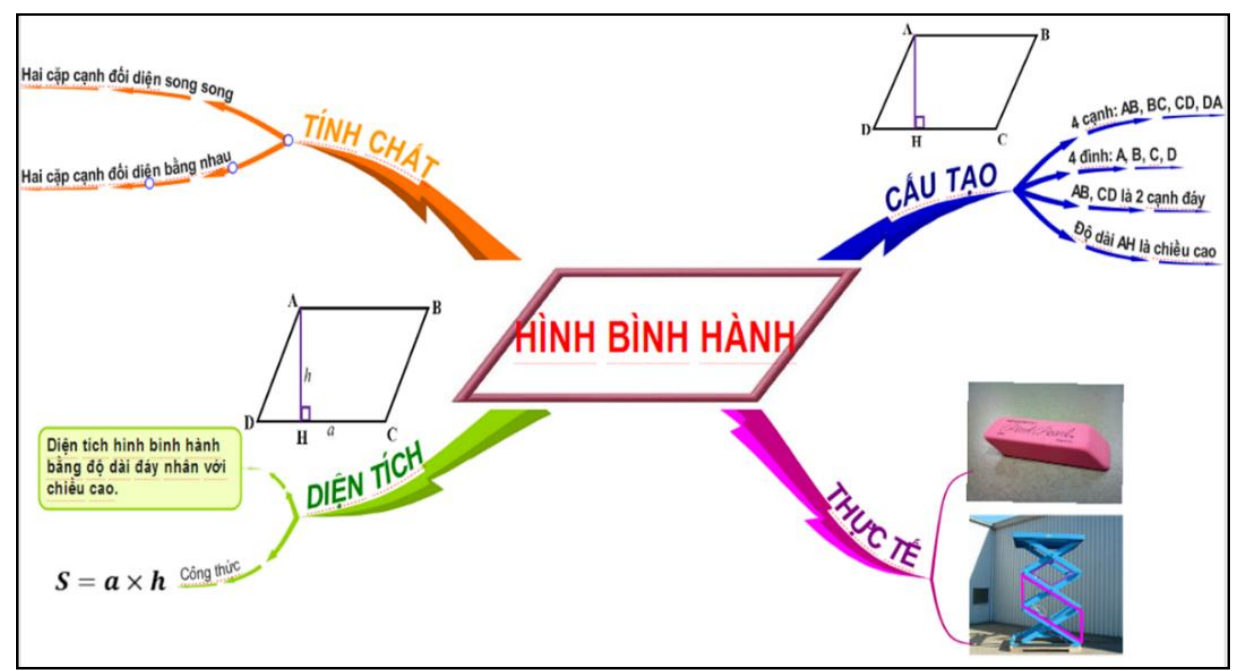

Figure 2: Mind map of the lesson "Parallelogram"

- Requirements: Coloring the topic image prominently; coloring the main branches (level 1) and keywords in different colors to distinguish them; colors of the branches closer to the central topic have to stand out from the branch farther away from the central topic; painting or adding appropriate, realistic images if possible.

- Evaluating students' products and analyzing the students' mistakes, and guiding students to overcome them.

Phase 2: Students draw and color the mind map of "Rhombus".

- The teacher prompts students to repeat the knowledge they have learned about rhombus: How is a rhombus structured? What are the properties of a rhombus? State the rule for calculating the area of a rhombus?

- Teacher instructs students to draw and color a mind map to review the knowledge of the lesson "Rhombus": The central topic is a rhombus; what can we draw and color there? How many main branches can we draw from the central topic? What are the titles of these branches? What sub-branches can be drawn from each main branch? What more pictures can we draw related to rhombus? In reality, what do we see shaped like a rhombus? What color will the sub-branches be compared to other main branches? What is the shape and color of the main branch compared to the level 2 and 3 branches? 
- Teacher hands out A4 paper and asks students to draw and color a mind map of "Rhombus" in 20 minutes.

- Requirements: Students can draw a complete mind map by themselves, with three or more branches, exact keywords and knowledge. The central topic stands out; the main branches are thicker (larger) or more prominently colored than the sub-branches; the main branches are colored differently to distinguish from each other.

- Evaluating students' products and analyzing the students' mistakes, and guiding students to overcome them.

\subsubsection{Instrument}

A mind map-making procedure is shown in Figure 3.

\section{Drawing central topic}

Drawing main branches (level 1)

Drawing sub-branches

Adding illustrating images

Figure 3: The 4-step model of creating a mind map

Step 1: Drawing the central topic. Students need to draw the central topic from which other ideas are developed. Students can draw large-sized images with surrounding colors so that the subject stands out and attracts attention. The topic draw should not be framed or obscured. Words can be added to the topic drawing if the topic is not clear.

Step 2: Drawing main branches (level 1). The branch titles are the main points or ideas of the topic, arranged around the central topic and connected to the central topic by bold lines. Level 1 branches should be drawn diagonally so that more sub-branches can be deployed more easily. The keywords in the title need to be brief, concise and be differentiated in color and size.

Step 3: Drawing sub-branches. Sub-branches are branches that are developed from sub-branches of level 1. These are the detailed contents of the main ideas. Level 2, 3 branches (maybe more, depending on topic content) will be connected by thin lines and merged into level 1 branches. It is recommended to draw more branches connected by curves than straight lines; this will make the mind map not rigid and more flexible, thus easier to remember. Keywords and symbols should be used in each branch, and only one keyword should be used. This makes it easy for new keywords and other ideas to be appended to existing keywords. All branches should have the same color to distinguish the content of the branches easily. 
Step 4: Adding illustrating images. In this step, to enhance the imagination and make the brain remember knowledge more easily, students can add more illustrations or annotate some ideas to increase the richness of the content and the effectiveness of the mind map.

During the experiment, the research team designed lessons with the support of mind maps, based on the requirements of teaching geometry for students of grade 4 as specified in the current curriculum: Students are required to be able to (1) identify and correctly name acute, obtuse, and flat angles, know its relationship with right angles and recognize angles in learned shapes; (2) identify relationships between two lines such as: intersecting, perpendicular to each other, parallel to each other; (3) identify the features of the sides of parallelograms and rhombus, know how to calculate the area of a parallelogram, a rhombus; (4) know how to draw squares, rectangles according to the measure of sides (with a ruler); know how to cut, match, and fold shapes (with samples); (5) initially develop thinking manipulations, geometric imagination; (6) know how to apply formulas to solve problems with geometric content.

\section{Results and Discussion}

\subsection{The results of familiarizing and coloring the designed mind map}

The results obtained from students' designed mind map coloring of "Parallelogram" are shown in Table 1:

Table 1: Results of coloring mind map

\begin{tabular}{|l|c|c|}
\hline & Number & Percentage \\
\hline Good & 29 & $65.91 \%$ \\
\hline Not good & 15 & $34.09 \%$ \\
\hline
\end{tabular}

In Table 1, the number of a well-colored mind map is 29 , accounting for $65.91 \%$, the number of an unsatisfactory mind map is 15 , accounting for $34.09 \%$ of total mind maps obtained. The results were very positive, showing that most students understood how to represent the central topic and the levels of branches in the mind map. Furthermore, the colors in each diagram represent the individual identity of each student. Here are some illustrations of good mind maps (Figure 4, 5, 6). 


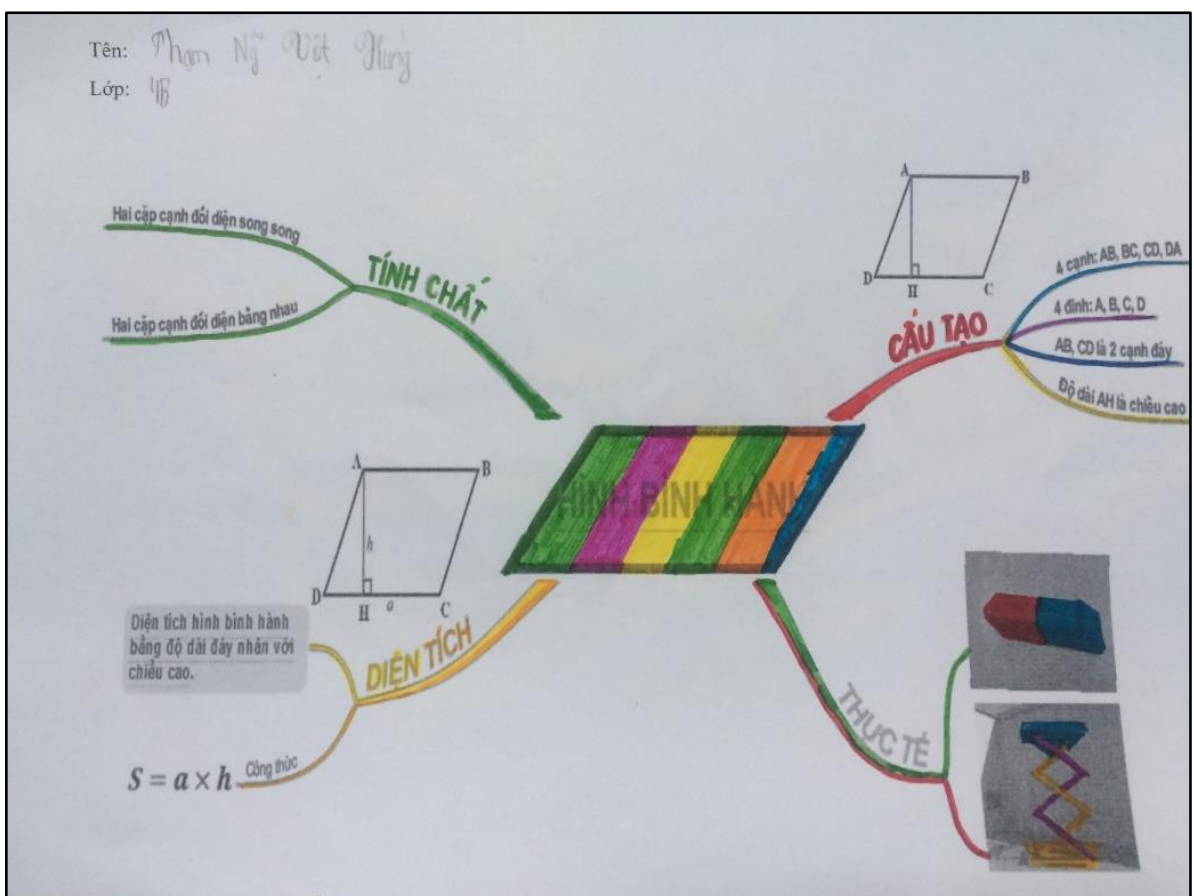

Figure 4: Good mind map of the lesson "Parallelograms"

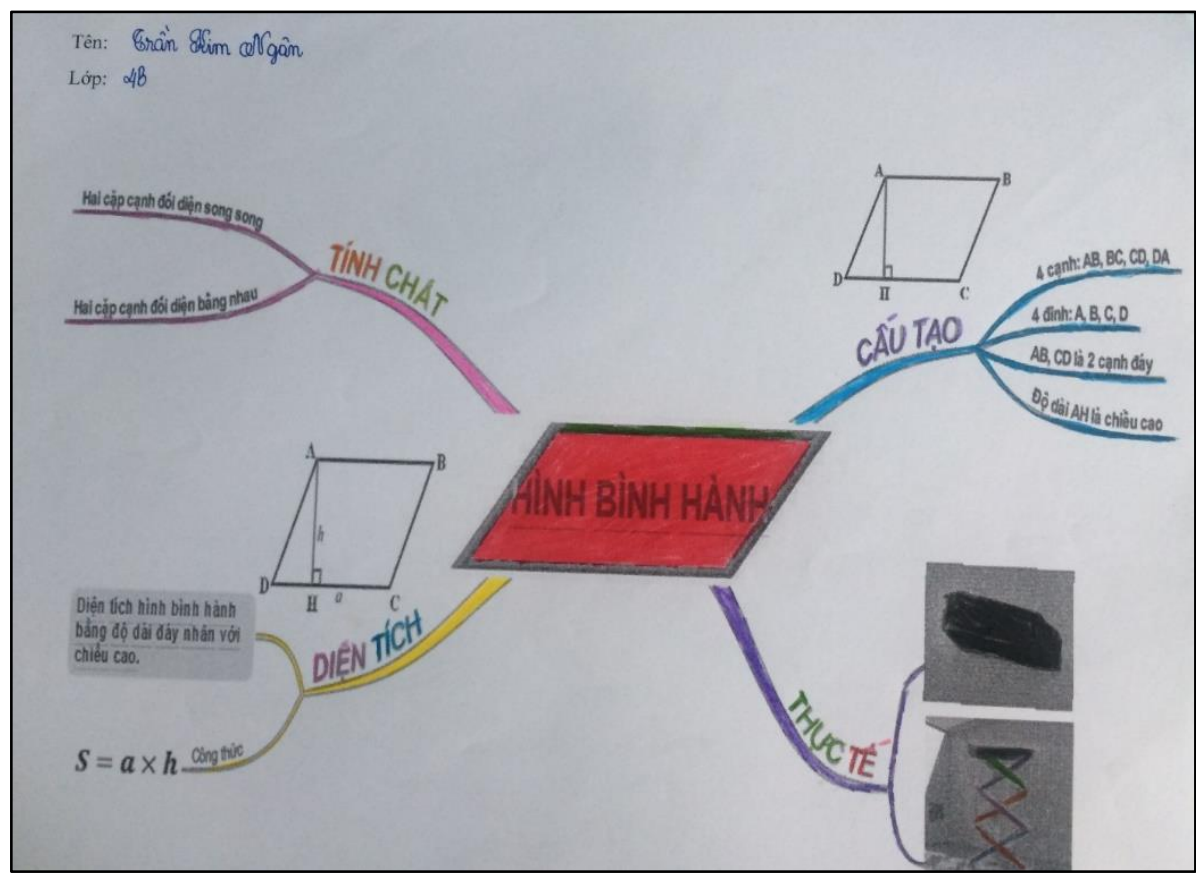

Figure 5: Good mind map of the lesson "Parallelograms" 


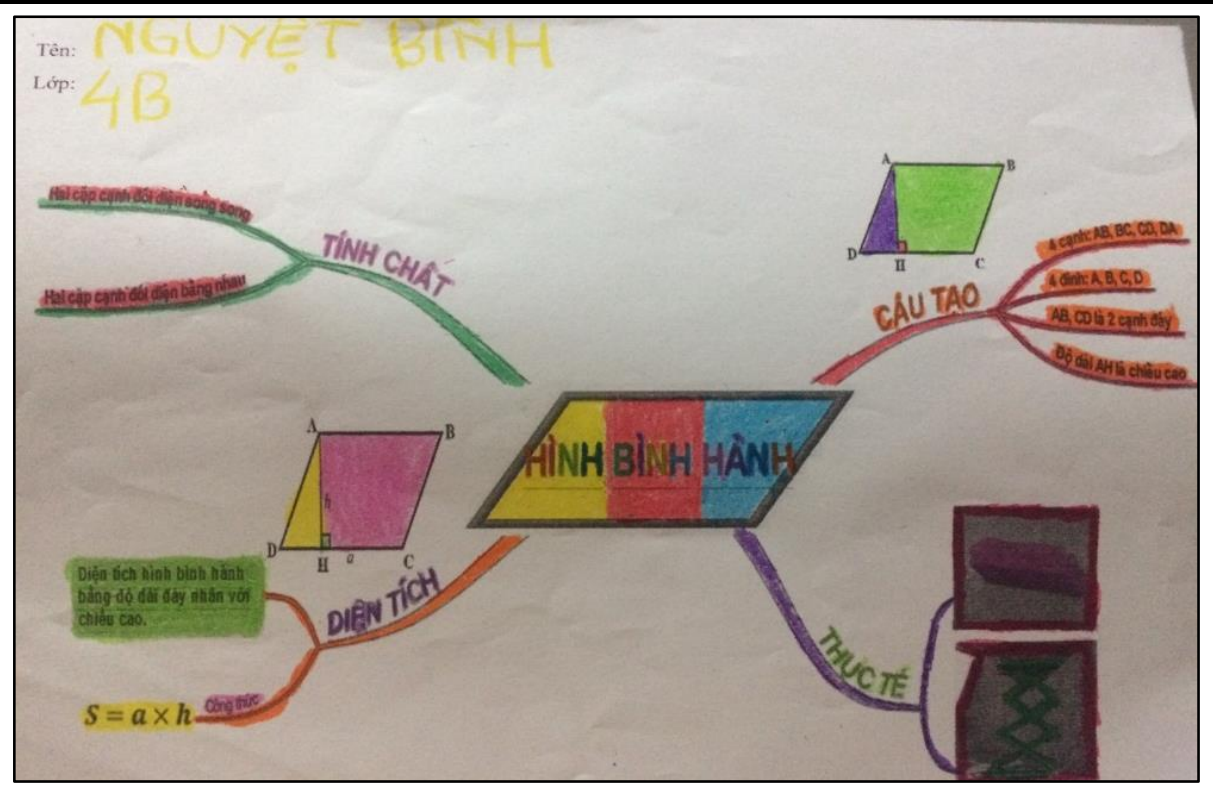

Figure 6: Good mind map of the lesson "Parallelograms"

In addition, there is some mind maps not colored appropriately. Children often mistake not distinguishing between different branches and coloring the main branches without clearly distinguishing colors. Here are some illustrations; see Figures 7, 8.

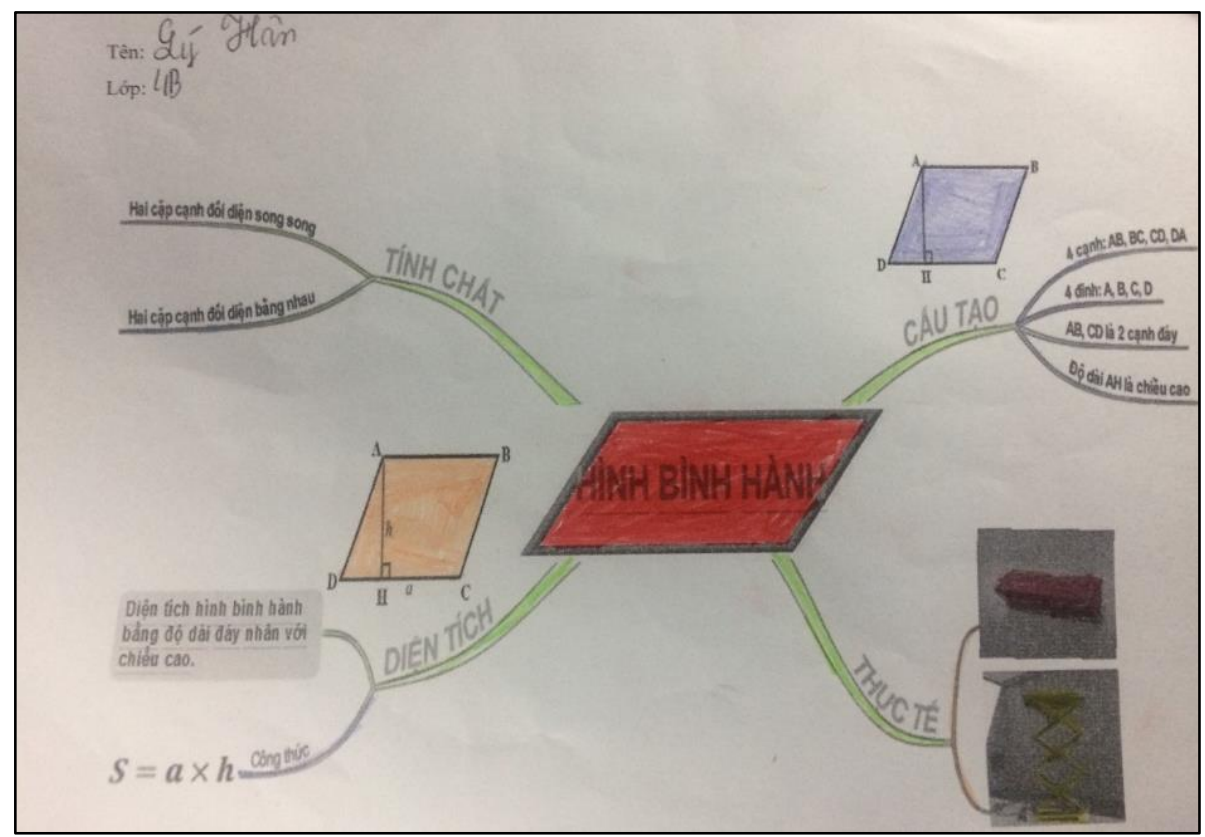

Figure 7: Not-good mind map of the lesson "Parallelogram" 


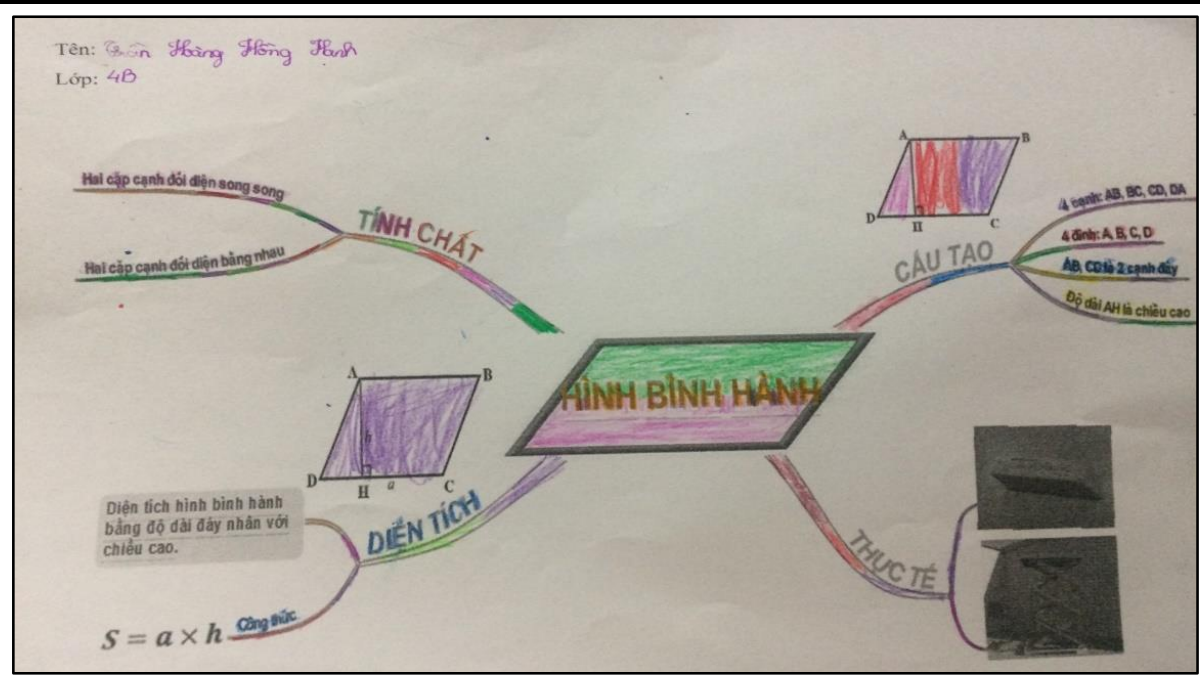

Figure 8: Not-good mind map of the lesson "Parallelogram"

\subsection{Results of students' drawing and coloring their mind maps to review knowledge in the lesson Rhombus}

The results obtained from allowing students to draw and color the "Rhombus" mind map by themselves are shown in Table 2:

Table 2: Results of drawing and coloring mind map

\begin{tabular}{|l|c|c|}
\hline & Number & Percentage \\
\hline Good & 34 & $77.27 \%$ \\
\hline Not good & 10 & $22.73 \%$ \\
\hline
\end{tabular}

According to the quality assessment of the mind maps students create to review their knowledge of the Rhombus lesson, there are 34 good mind maps, accounting for $72.27 \%$, and ten inappropriate mind maps, accounting for $27.73 \%$, in the table above. The results show that even though they have only just been acquainted with and approached the use of digital maps in reviewing geometry lessons through Phase 1, most students can already draw a complete mind map by themselves to review the knowledge of the lesson "Rhombus" in particular as well as review the knowledge of geometry in general. Through classroom observation, it can be noticed that the children drew mind maps with enthusiasm and excitement. The mind map of the geometry knowledge with colors, images, and connections drawn by themselves makes students feel more interested in the subject, motivating them to learn and deepen their knowledge. Here are some illustrations of good mind maps (Figures 9, 10, 11, 12, 13): 


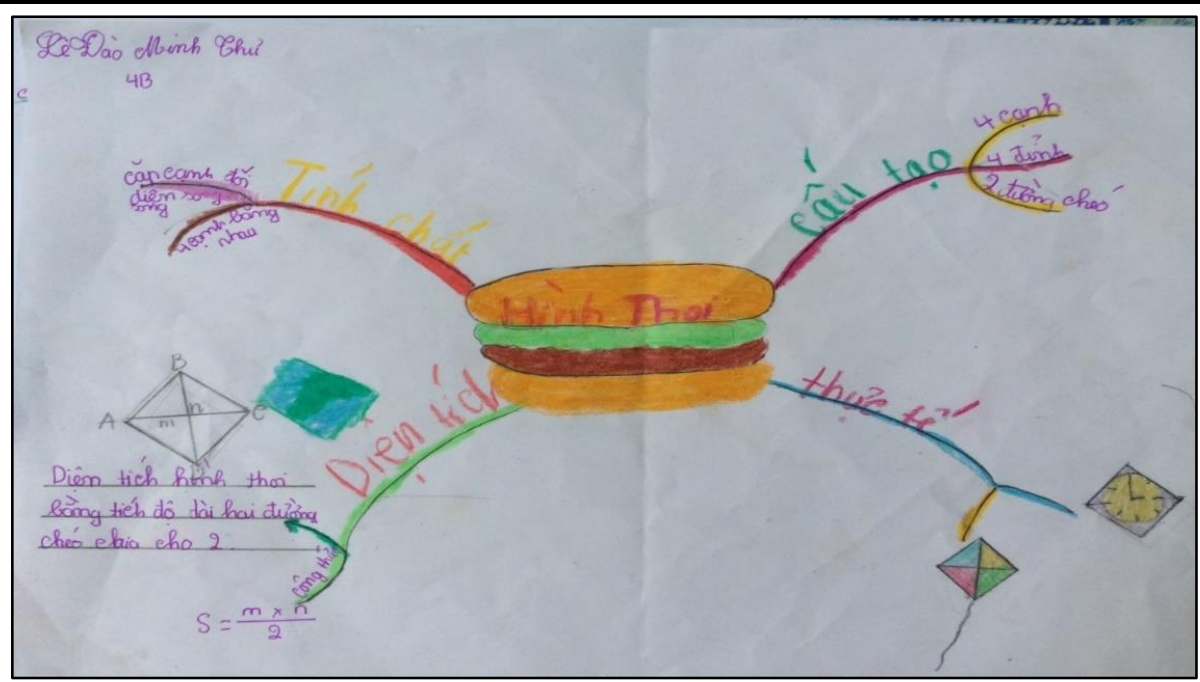

Figure 9: Good mind map of the lesson "Rhombus"

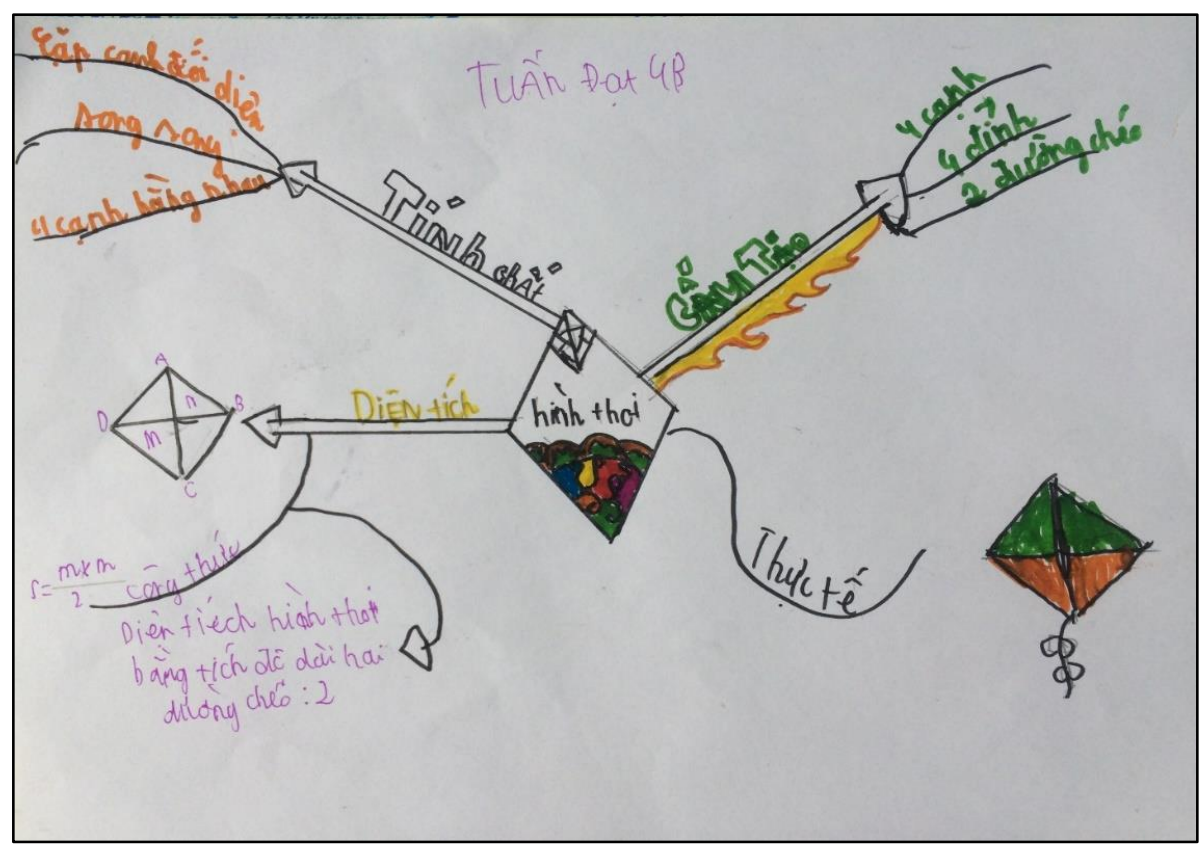

Figure 10: Good mind map of the lesson "Rhombus" 


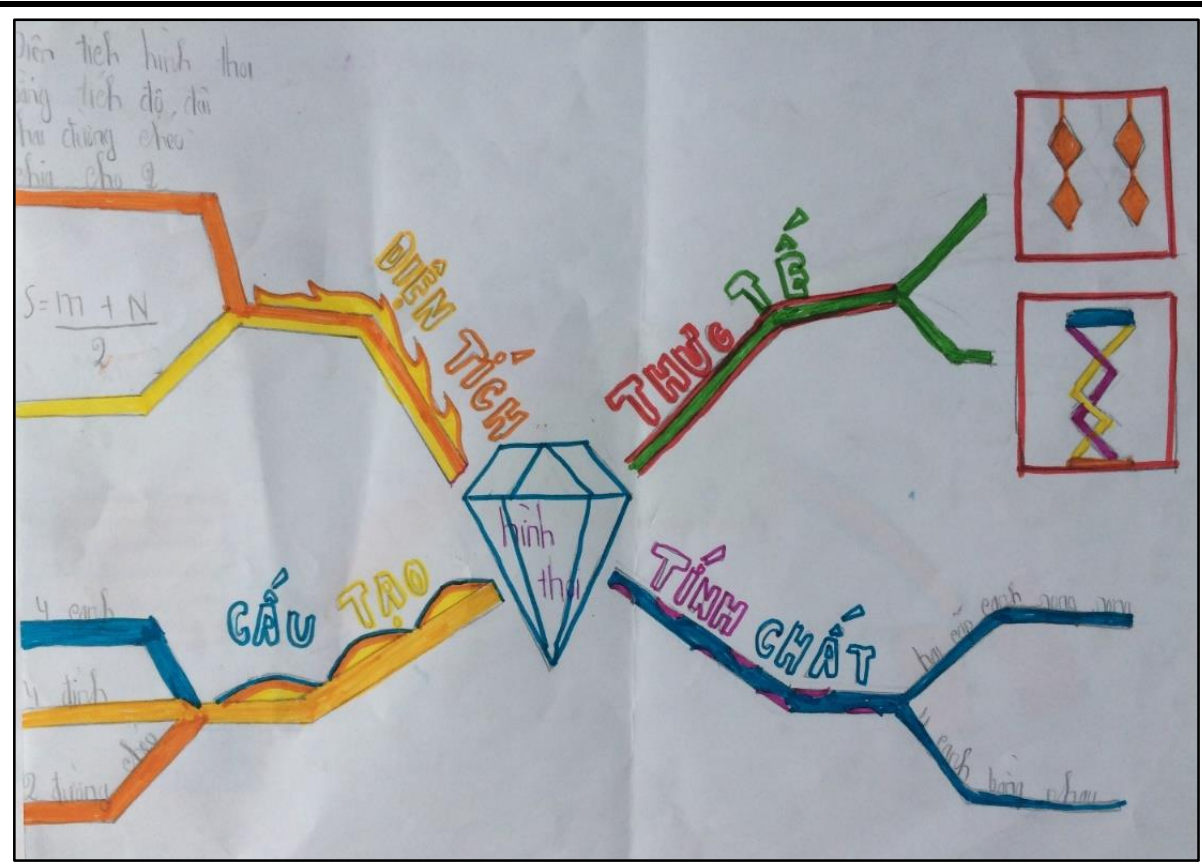

Figure 11: Good mind map of the lesson "Rhombus"

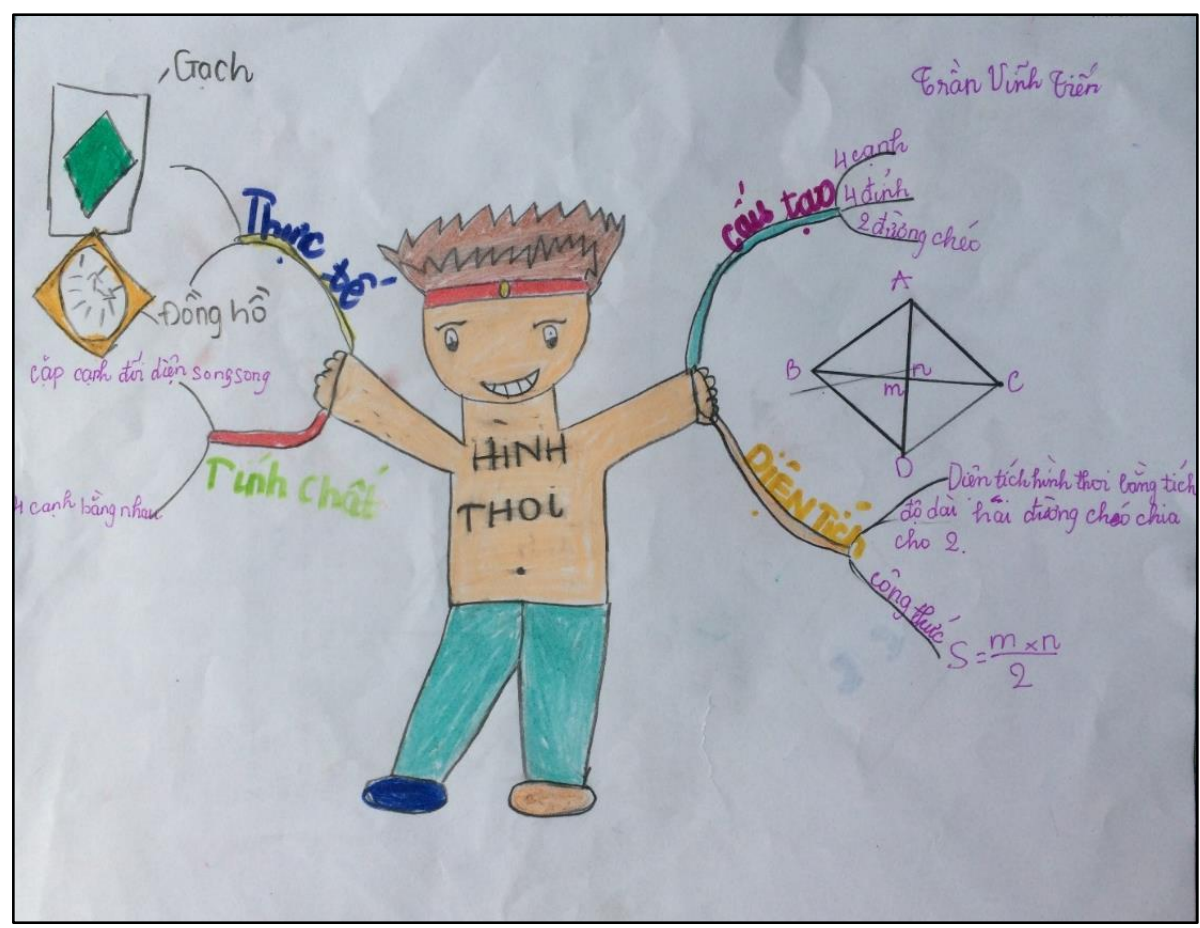

Figure 12: Good mind map of the lesson "Rhombus" 


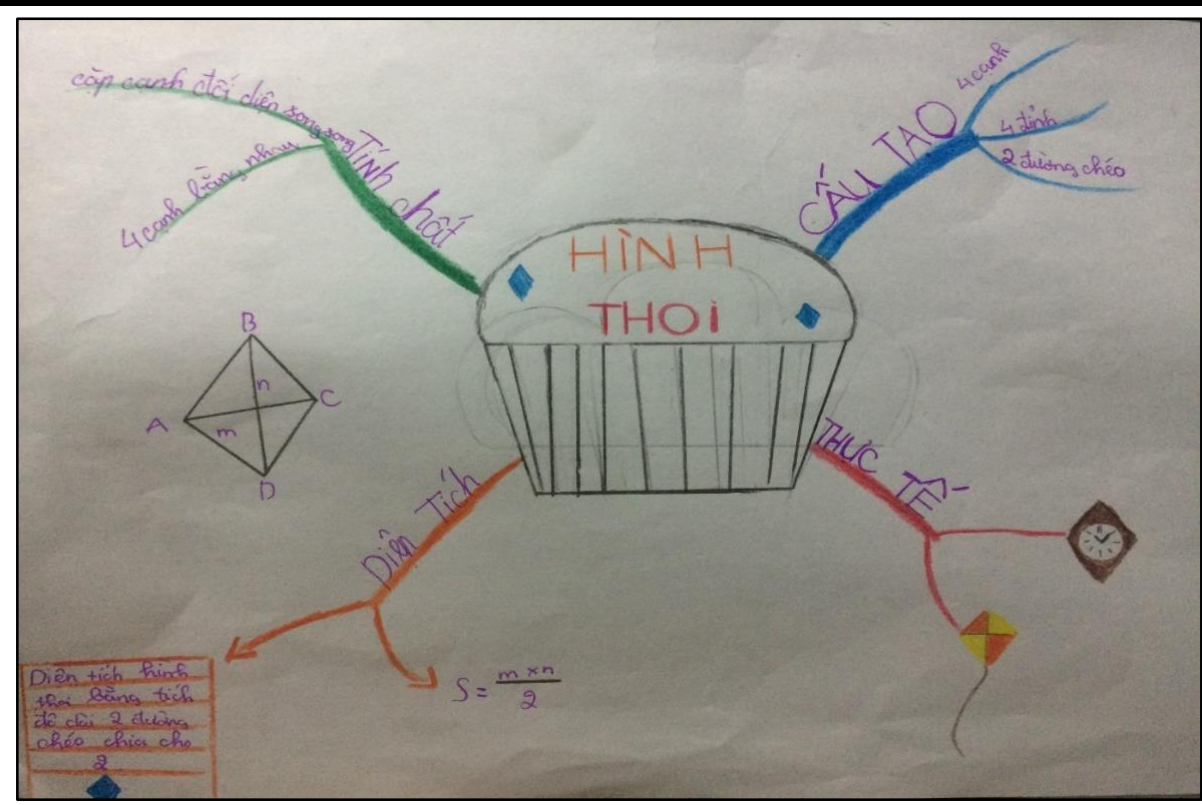

Figure 13: Good mind map of the lesson "Rhombus"

Besides, $22.73 \%$ of the mind maps did not meet the requirements because the children still drew the main branches and the sub-branches that did not clearly show the level and used inappropriate colors. Figures 14, 15 are some illustrations:

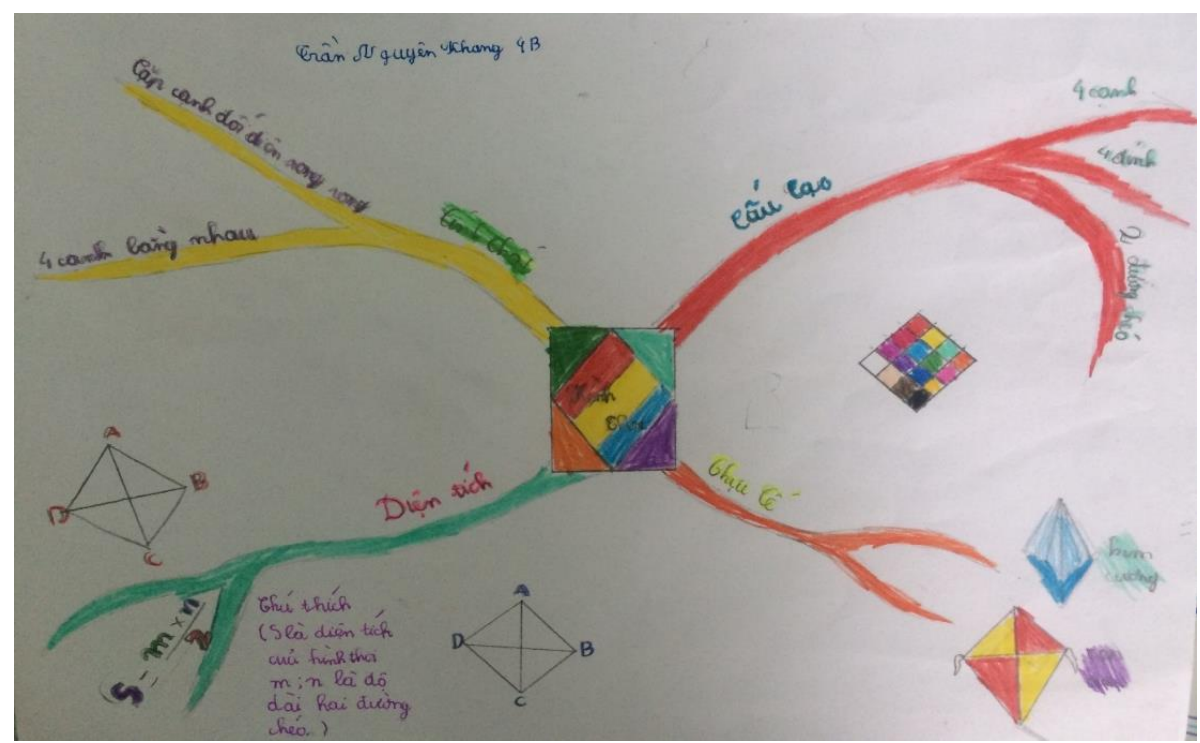

Figure 14: Not-good mind map of the lesson "Rhombus" 


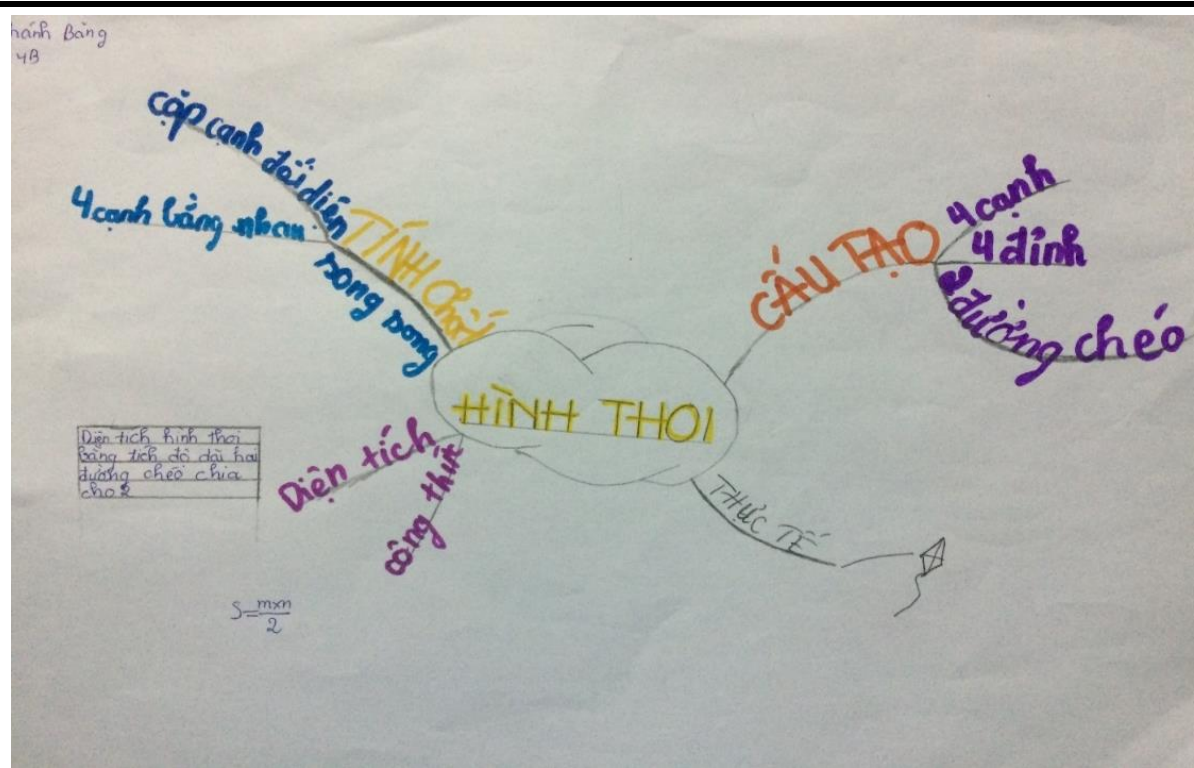

Figure 15: Not-good mind map of the lesson "Rhombus"

\subsection{Results of students' survey}

The results of interviewing 44 students through questionnaires obtained the following results:

Question 1: How do you like using mind maps to review geometry knowledge?

Students' attitudes towards using mind maps to review geometry knowledge are shown in Table 3:

Table 3: Results of Question 1

\begin{tabular}{|l|c|c|}
\hline & Number of students & Percentage (\%) \\
\hline Extremely like & 20 & 45.45 \\
\hline Like & 17 & 38.64 \\
\hline Neutral & 7 & 15.91 \\
\hline Dislike & 0 & 0 \\
\hline Extremely dislike & 0 & 0 \\
\hline
\end{tabular}

In Table 3, the percentage of students choosing the Extremely like and Like level accounted for $84.09 \%$. Most students like to use the mind map to review the knowledge of geometry in particular and mathematics in general. The remaining $15.91 \%$ of students chose the level of Neutral, accounting for a relatively low rate. Especially, no student chose the level of Dislike and Extremely disliked. This result shows that using a mind map to review mathematical knowledge for students is feasible and suitable to their actual needs and interests.

Question 2: Can you draw a mind map yourself to review mathematics knowledge? The results are shown in Table 4: 
Table 4: Results of Question 2

\begin{tabular}{|l|c|c|}
\hline & Number of students & Percentage (\%) \\
\hline Yes & 38 & 86.36 \\
\hline No & 6 & 13.64 \\
\hline
\end{tabular}

Table 4 shows that $86.36 \%$ of the students surveyed claim to draw mind maps on their own. This high rate proves that most students have mastered the basic steps to draw a mind map and are confident that they can draw one by themselves to review mathematics knowledge. The number of students who feel unable to draw by themselves accounts for a very low percentage, specifically $13.64 \%$ of the surveyed students.

Question 3: What are common difficulties you encountered when drawing mind maps to review geometry knowledge?

The results of the survey on students' difficulties when drawing a map are shown in Table 5:

Table 5: Results of Question 3

\begin{tabular}{|l|c|}
\hline & Number of choices \\
\hline It is hard to find ideas, illustrate images & 32 \\
\hline It is difficult to organize ideas & 28 \\
\hline It is difficult to identify and distinguish different levels of branches & 9 \\
\hline Drawing ability is not good & 8 \\
\hline It is difficult to represent the central topic & 4 \\
\hline
\end{tabular}

Through Table 5, it can be concluded that students find the most popular difficulties when drawing mind maps are finding ideas and images and organizing them, with a high number of choices are 32 and 28, respectively. Teachers need to pay attention to help students overcome these difficulties. To get accurate ideas and organize them logically, teachers can suggest that students find and organize collected ideas individually and through discussion groups. Besides, there are some other difficulties with a relatively low number of choices, such as difficulty identifying and distinguishing the levels of branches with nine students, drawing ability with eight students, and difficulty in representing the central topic with four students. Teachers also need to support students overcome these obstacles to become more confident to draw a mind map to review mathematics knowledge. With the difficulties related to the structure of a mind map, teachers can re-instruct the process of creating a mind map more detailed, introducing and analyzing some good mind maps to enhance students' understanding of drawing a mind map.

Question 4: What do you think about the benefits of applying mind maps to review geometry?

The results of students' opinions about the benefits of using mind maps to review geometry are shown in Table 4: 


\begin{tabular}{|l|c|}
\hline \multicolumn{2}{|c|}{ Table 6: Results of Question 4 } \\
\hline \multicolumn{2}{|c|}{} \\
\hline Long-term memory & Number of choices \\
\hline Stimulating creativity & 39 \\
\hline Faster memorization & 25 \\
\hline Brief knowledge organization & 22 \\
\hline Subject interests & 20 \\
\hline
\end{tabular}

The students' survey results about the benefits of using mind maps to review geometry knowledge in Table 6 show that most students think mind maps help to remember knowledge longer (39/44 students). The students themselves create funny drawings and harmonious colors on the mind map to review the lesson, so that knowledge will naturally and deeply be engraved. Stimulating creativity is a benefit that also accounted for the second-highest number of votes, with up to 32/44 students choosing. Use a mind map to help students break free of old ways of thinking and unleash their creative potential in notebooks and on paper. Thereby, it stimulates the activity of the left brain to increase the efficiency of memory and creativity. Other benefits such as faster memorization, brief knowledge organization, and raising subject interests accounted for a high number of votes, around $50 \%$. In addition, students also add some benefits such as: making them smarter, helping them know how to match colors. The above results show that a map is undoubtedly a useful tool that supports the review of geometry and mathematics knowledge of students. It also makes them more relaxed in class, which fosters the development of important skills for students, such as creativity, logical reasoning, and self-study.

Question 5: How do you think about applying a mind map in other activities?

Students' opinions on applying mind maps to other activities are shown in Table 7:

Table 7: Results of Question 5

\begin{tabular}{|l|c|}
\hline & Number of choices \\
\hline Studying and reviewing other subjects & 38 \\
\hline Planning & 9 \\
\hline Representing interests & 2 \\
\hline Decorating & 1 \\
\hline
\end{tabular}

In addition to reviewing the knowledge of geometry, most students also think that mind maps can also be used to review and study other subjects such as Geography, Science, History, English, Vietnamese, Writing. Besides, students think that a mind map can also be used to plan for an exam or meals, to show students' interests, summarize the interests of family members, and decorate. The mind map has various applications in many areas of life and especially in learning and reviewing knowledge.

With the results obtained from two experimental parts, students can familiarize themselves with a mind map and draw a mind map themselves to review their 
knowledge of geometry. Through students' opinion surveys and classroom observations, the research team found that using a mind map in teaching geometry for grade 4 primary students is effective, especially in reviewing students' knowledge.

Primary students especially like vivid, colorful pictures and especially love to draw. Drawing and coloring their mind maps to review mathematics knowledge can raise their interests and help deepen their knowledge. Although they have just approached the mind map through two experimental phases, most students have grasped the process and principles and can draw complete mind maps themselves. This successful result is beyond expectations and shows that using a mind map in geometry is appropriate and suitable for primary students, especially for grades 4 and 5 . In addition, the student's identity shows the pure and naughty thinking of the primary school age, and it also shows the very creative thinking of each student. In addition, a mind map also supports students in thinking and relating geometry knowledge with real-life phenomena, making it easier to understand and deepen students' understanding.

\section{Conclusion}

Through the experimental process, the research team found that a mind map is an effective and suitable tool supporting teaching geometry in grade 4 . Applications of mind maps in teaching mathematics can raise the interests of students. The introduction of a mind map into the subject has created a positive atmosphere for the class, aroused interest and motivation in students' learning (Anas et al., 2018; Cendros Araujo \& Gadanidis, 2020; Dhindsa et al., 2011; Erdem, 2017; Liu et al., 2015; Stokhof et al., 2019). Moreover, most students can draw a mind map following a complete mind map; each mind map shows students' style. The mind map has various colors and playful images suitable for primary age but still ensures the correct content of mathematics knowledge and the characteristics of mind maps. The geometry knowledge combined with colors and funny images from the mind maps makes the subject more interesting and helps students remember the knowledge they have learned deeply. This result is consistent with the study of the authors Dhindsa et al (2011); Santiago (2011); Liu et al. (2015); D'Onofrio et al. (2017); Erdem (2017); Anas et al. (2018); Mercie et al. (2021); Pribadi and Susilana (2021). The experimental process shows that this mathematics tool supports very well the review of geometry knowledge for students. Therefore, using mind maps in teaching geometry in grade 4 is suitable with the subject's characteristics, primary students' age characteristics, and the "studentcentered" educational perspective (Stokhof et al., 2019; Stokhof et al., 2020).

In addition to the positive results achieved, there are also some limitations of the study, such as some students are still unfamiliar with withdrawing a mind map; it is difficult to manage the classroom, and the students' drawing time is relatively long under short-term experiments.

From the results and limitations of the study, new studies can be carried out on applying mind mapping software or online drawing tools, using mind map evaluation 
software to grade students' products. In addition, studies can be conducted with a longterm plan, with a larger number of students, in various content and levels of study.

\section{Conflict of Interest Statement}

The authors declare no conflicts of interests.

\section{About the Authors}

Lu Kim Ngan graduated with honors from Can Tho University with a Master's degree in Mathematics Education. The field of education holds a special interest for her, and she has a strong interest in scientific research in this area.

Duong Huu Tong is an associate professor and senior lecturer at Can Tho University's School of Education in Can Tho City, Vietnam. He also works as a consultant in addition to his academic positions. Over the past 17 years, he has developed expertise in various fields, including mathematics education, educational evaluation, and curriculum development, among others.

Bui Phuong Uyen works as a principal lecturer at Can Tho University's School of Education. In 2016, she received her doctorate in mathematics education. In particular, she is interested in developing students' capacity for learning, testing and assessing student learning outcomes, and using information technology in teaching and learning settings.

Nguyen Duc Minh is a final-year student at Can Tho University's School of Education, majoring in Primary Education. The pursuit of scientific knowledge excites him, especially when it comes to developing active teaching methods.

\section{References}

Anas, N. et al. (2019). Usefulness and Effectiveness of Mind Mapping: An Analysis of CTU101 and CTU151 Courses. In: Mohamad Noor M., Ahmad B., Ismail M., Hashim H., Abdullah Baharum M. (eds) Proceedings of the Regional Conference on Science, Technology and Social Sciences (RCSTSS 2016). Springer, Singapore. https://doi.org/10.1007/978-981-13-0203-9 51

Arthur, K. (2012). Mind maps: Improve memory, concentration, communication, organization, creativity, and time management. http://www.amazon.com/

Bhattacharya, D., \& Mohalik, R. (2020). Digital mind mapping software: A new horizon in the modern teaching-learning strategy. Journal of Advances in Education and Philosophy, 4(10) 400-406. https://doi.org/10.36348/jaep.2020.v04i10.001

Buran, A., \& Filyukov, A. (2015). Mind mapping technique in language learning. ProcediaSocial and Behavioral Sciences, 206, 215- 218. https://doi.org/10.1016/j.sbspro.2015.10.010

Cendros Araujo, R., Gadanidis, G. (2020). Online collaborative mind mapping in a mathematics teacher education program: a study on student interaction and 
knowledge construction. ZDM Mathematics Education, 52,943-958. https://doi.org/10.1007/s11858-019-01125-w

D'Antoni, A.V., Zipp, G. P., Olson, V. G. et al. (2010). Does the mind map learning strategy facilitate information retrieval and critical thinking in medical students?. BMC Med Educ, 10(61). https://doi.org/10.1186/1472-6920-10-61

D'Onofrio S., Portmann E., Kaltenrieder P., Myrach T. (2017). Enhanced Knowledge Management by Synchronizing Mind Maps and Fuzzy Cognitive Maps. In: Meier A., Portmann E., Stoffel K., Terán L. (eds) The Application of Fuzzy Logic for Managerial Decision Making Processes. Fuzzy Management Methods. Springer, Cham. https://doi.org/10.1007/978-3-319-54048-1 2

Dhindsa, H. S., Makarimi-Kasim \& Roger Anderson, O. (2011). Constructivist-Visual Mind Map Teaching Approach and the Quality of Students' Cognitive Structures. J Sci Educ Technol, 20, 186-200. https://doi.org/10.1007/s10956-010-9245-4

Erdem, A. (2017). Mind Maps as a Lifelong Learning Tool. Universal Journal of Educational Research, 5(12A), 1 - 7. https://doi.org/10.13189/ujer.2017.051301.

Jones, R., Koonce, J., \& Snyder, P. (2012). The effects of mind mapping activities on students' motivation. International Journal for the Scholarship of Teaching and Learning, 6(1), 1-21. https://doi.org/10.20429/ijsotl.2012.060105

Liu, Xq., Zhang, Tx., Tao, L.et al. (2015). Online mindmap as interface of electronic resource integration and sharing. J. Shanghai Jiaotong Univ. (Sci.), 20, 101-105 https://doi.org/10.1007/s12204-015-1595-x

Maksimenkova O., Neznanov A., Papushina I., Parinov A. (2018). On Mind Maps Evaluation: A Case of an Automatic Grader Development. In: Auer M., Guralnick D., Simonics I. (eds) Teaching and Learning in a Digital World. ICL 2017. Advances in Intelligent Systems and Computing, 716. Springer, Cham. https://doi.org/10.1007/978-3-319-73204-6 25

Mamontova M., Starichenko B., Novoselov S., Kusova M. (2016). Use of Electronic Mind Maps for Creation of Flexible Educational Information Environments. In: Uskov V., Howlett R., Jain L. (eds) Smart Education and e-Learning 2016. Smart Innovation, Systems and Technologies, vol 59. Springer, Cham. https://doi.org/10.1007/978-3-319-39690-3 54

Merchie, E., Catrysse, L. \& Van Keer, H. (2021). Mind maps as primers when reading-forlearning in elementary grades? An eye tracking study. Instr Sci, 49, 23-65. https://doi.org/10.1007/s11251-020-09529-y

Norman, R. R. (2012). Reading the graphics: What is the relationship between graphical reading processes and student comprehension?. Reading and Writing, 25(3), 739774. https://doi.org/10.1007/s11145-011-9298-7.

Pribadi, B. A., \& Susilana, R. (2021). The use of mind mapping approach to facilitate students' distance learning in writing modular based on printed learning materials. European Journal of Educational Research, 10(2), 907-917. https://doi.org/10.12973/eu-jer.10.2.907

Santiago, H. C. (2011). Visual Mapping to Enhance Learning and Critical Thinking Skills. Optometric Education, 36(3), 125-139. 
Serrat O. (2017). Drawing Mind Maps. In: Knowledge Solutions. Springer, Singapore. https://doi.org/10.1007/978-981-10-0983-9 65

Stokhof, H., de Vries, B., Bastiaens, T. et al. (2019). Mind Map Our Way into Effective Student Questioning: A Principle-Based Scenario. Res Sci Educ, 49, 347-369. https://doi.org/10.1007/s11165-017-9625-3

Stokhof, H., de Vries, B., Bastiaens, T. et al. (2020). Using Mind Maps to Make Student Questioning Effective: Learning Outcomes of a Principle-Based Scenario for Teacher Guidance. Res Sci Educ, 50, 203-225. https://doi.org/10.1007/s11165-017$\underline{9686-3}$

Tony Buzan Learning Centre (2021, October 15). https://www.tonybuzan.edu.sg/course/effective-mind-mapping-skills/

Wang S., Ding J., Xu Q., Wei X., Xu Q., Dilinar B. (2014) Application of Mind Map in Teaching and Learning of Medical Immunology. In: Li S., Jin Q., Jiang X., Park J. (eds) Frontier and Future Development of Information Technology in Medicine and Education. Lecture Notes in Electrical Engineering, 269. Springer, Dordrecht. https://doi.org/10.1007/978-94-007-7618-0 251 
Lu Kim Ngan, Duong Huu Tong, Bui Phuong Uyen, Nguyen Duc Minh

Creative Commons licensing terms

Author(s) will retain the copyright of their published articles agreeing that a Creative Commons Attribution 4.0 International License (CC BY 4.0) terms will be applied to their work. Under the terms of this license, no permission is required from the author(s) or publisher for members of the community to copy, distribute, transmit or adapt the article content, providing a proper, prominent and unambiguous attribution to the authors in a manner that makes clear that the materials are being reused under permission of a Creative Commons License. Views, opinions and conclusions expressed in this research article are views, opinions and conclusions of the author(s). Open Access Publishing Group and European Journal of Education Studies shall not be responsible or answerable for any loss, damage or liability caused in relation to/arising out of conflicts of interest, copyright violations and inappropriate or inaccurate use of any kind content related or integrated into the research work. All the published works are meeting the Open Access Publishing requirements and can be freely accessed, shared, modified, distributed and used in educational, commercial and non-commercial purposes under a Creative Commons Attribution 4.0 International License (CC BY 4.0). 